\title{
Pap smear screening: a retrospective study
}

\author{
Anjali Soni* \\ Department of Obstetrics and Gynecology, Gujarat Medical Education and Research Society Medical College, Gotri, \\ Vadodara, Gujarat, India
}

Received: 24 January 2017

Revised: 15 February 2017

Accepted: 27 February 2017

\author{
*Correspondence: \\ Dr. Anjali Soni, \\ E-mail: drsonianjali@gmail.com
}

Copyright: $\odot$ the author(s), publisher and licensee Medip Academy. This is an open-access article distributed under the terms of the Creative Commons Attribution Non-Commercial License, which permits unrestricted non-commercial use, distribution, and reproduction in any medium, provided the original work is properly cited.

\begin{abstract}
Background: Cervical cancer is the seventh cancer in overall frequency, but the second most common cancer among women worldwide. The objective was to study the population undergoing pap-smear screening.

Methods: It is retrospective study conducted in general hospital, GMERS Medical College Gotri, Gujarat, India. Total 1003 patients who attended OPD have undergone routine pap smear screening over period of 6 months from January 2016 to June 2016. Cytotological examination was done and test results were classified according to Bethesda system.

Results: Abnormal tests were found in 36 patients.

Conclusions: Pap smear a routine screening test offered to every woman who comes to our OPD irrespective of her complaints. Every woman at least once in her lifetime should go for pap-smear examination. It is effective screening test for cervical carcinoma. It is cost effective test with high specificity and very easy to perform so it becomes the method of choice for cervical carcinoma screening. With proper follow up patients with abnormal tests are screened and appropriate treatment is being offered to patients.
\end{abstract}

Keywords: Cervical cancer, Pap smear, Screening program

\section{INTRODUCTION}

Cervical cancer is the seventh cancer in overall frequency, but the second most common cancer among women worldwide. Cervical cancer is much more common in developing countries, where $83 \%$ of cases occur and where cervical cancer accounts for $15 \%$ of female cancers, with a risk before age 65 of $1.5 \%$. Cervical cancer is the commonest cancer cause of death among women in developing countries. ${ }^{1}$ In developed countries, cervical cancer accounts for only $3.6 \%$ of new cancers, with a cumulative risk (0 to 64$)$ of $0.8 \% .^{1-3}$

Every year in India, 122,844 women are diagnosed with cervical cancer and 67,477 die from the disease. ${ }^{4}$ India has a population of 432.2 million women aged 15 years and older who are at risk of developing cancer. ${ }^{4}$ It is the second most common cancer in women aged 15-44 years. ${ }^{4}$

The pap smear has been the method of choice for cervical cancer screening since the 1950s. In cytology, cells are scraped from the squamo-columnar junction of the cervix and fixed on a glass slide for reading by a trained cytologist. ${ }^{5}$ It is an effective tool for mass screening and detects lesions early enough for effective treatment. ${ }^{6}$ But pap smear screening has its own drawbacks. It has low sensitivity i.e. between $47-62 \%$, low predictive value and the subjective interpretation of the results. ${ }^{6}$ On the other hand, Pap smear testing also has strengths, such as wide acceptance, meeting most of the criteria for a good screening test in settings with adequate resources, obtaining 
a permanent record of the test in the form of a slide, and having a high specificity of $60-95 \% .^{6}$

\section{Aims and objective}

- To find out incidence of abnormal pathology by pap smear screening among patients visitesd in our opd setup

- To evaluate the impact of screening program on overall health outcome.

- To look for awareness of disease and its screening program.

- To look for appropriate follow up of patients with abnormal result and offer them treatment available in our set up.

\section{METHODS}

The study group included 1003 outdoor patients who attended OPD in OBGY department of GMERS Medical College and Hospital, Gotri, Gujarat, India. All married women who attended gynaec OPD had undergone pap smear screening as a routine check-up tool over the period of 6 months. The conventional pap smear test was used for cytology. During per speculum examination, cervical smears were taken from ectocervix and from endocervical canal with a Ayres spatula and endocervical brush respectively in two different slides for each patient. All of the smears were taken by the same person who was trained for this procedure before the study. Smears were fixed with ethanol and sent to the laboratory at the end of every working day. The laboratory was accredited for cytological testing, and evaluations of the smears were made by a pathologist. Regular follow up of the patient done after 7 days with cytology report.

Evaluation of the cervical cells was done using the Bethesda System 2001 as follows

1) Negative for intraepithelial lesion or malignancy.

2) Epithelial cell abnormalities.

a) Squamous cell

- Atypical squamous cells of undetermined significance (ASC-US).

- Low grade squamous intraepithelial lesion (LSIL) encompassing: human papilloma virus (HPV)/mild dysplasia/CIN 1.

- High grade squamous intraepithelial lesion (HSIL) encompassing: moderate and severe dysplasia, CIS/CIN 2 and CIN3 with features suspicious for invasion (if invasion is suspected).

- Squamous cell carcinoma.

b) Glandular cell

- Atypical.
- Endocervical adenocarcinoma in situ.

- Adenocarcinoma.

3) Other malignant neoplasms.

\section{RESULTS}

Table 1 show that patients who attended OPD were having wide range of age variation. Below 20 years- 34 patients, from 21 to 30 years- 386, from 31 to 40 years324 , from 41 to 50 years- 17 , from 51 to 60 years- 53, from 61 to 70 years- 28 and from 71 to 80 years- 6 patients were there. Maximum numbers of patients were from reproductive age group i.e. total 510.

Table 1: Age distribution.

\begin{tabular}{|l|l|}
\hline Age & Number of patients \\
\hline Upto 20 & 34 \\
\hline 21 to 30 & 386 \\
\hline 31 to 40 & 324 \\
\hline 41 to 50 & 172 \\
\hline 51 to 60 & 53 \\
\hline 61 to 70 & 28 \\
\hline 71 t0 80 & 6 \\
\hline
\end{tabular}

Table 2 shows that patients who attended OPD had come with various complaints like lower abdominal pain, white discharge, bleeding per vagina and infertility. Some patients had single complaints and some patients had multiple complaints. Out of 1003 patients 357 were having no obvious abnormal pathology in cervix on per speculum examination. Rest of the patients had nabothian follicles, erosion, ectropion and hypermia like cervical changes present.

Table 2: Findings of per speculum examination.

\begin{tabular}{|lll|}
\hline Cervical examination & No. of patient & Percentage \\
\hline Normal & 357 & 35.6 \\
\hline Nabothian follicles & 225 & 22.4 \\
\hline Erosion & 114 & 11.3 \\
\hline Ectropion & 57 & 5.7 \\
\hline Hyperemia & 250 & 25 \\
\hline
\end{tabular}

Table 3 Incidence of abnormality in examination of pap smear.

\begin{tabular}{|lll|}
\hline \multicolumn{2}{|c|}{ Abnormal pap smear results } \\
\hline ASCUS & 26 & $72.22 \%$ \\
\hline LSIL & 8 & $22.22 \%$ \\
\hline HSIL & 2 & 5.55 \\
\hline
\end{tabular}

Table 3 shows that total 1003 patients who have come to our OPD for different complaints have been screened. 36 Pap smear reports turned out to be abnormal. Out of 36 , $26(72.22 \%)$ were suggestive of atypical squamous cell of undetermined significance while 8 reports $(22.22 \%)$ 
were in category of low grade squamous intra epithelial lesion (LSIL) and 2 reports (5.55\%) were high grade squamous intra epithelial lesion. Patients with HSIL were immediately called for follow up and after proper counselling hysterectomy done in both the patients.

\section{DISCUSSION}

Cancer of the cervix has been the most important cancer among women in the past two decades. ${ }^{7}$ In India the peak age for cervical cancer incidence is $55-59$ years. ${ }^{8}$

Factors like sexual habits, reproductive factors, other sexually transmitted diseases, coinfection with HIV, smoking, nutritional deficiency, genetic susceptibility, use of hormonal contraceptives and high parity influence the progression of disease. ${ }^{9}$

The main aim of cervical screening is to prevent invasive cervical cancer from developing by detecting and treating women with CIN2/3 lesions. The critical components of a screening program are an acceptable good-quality screening test, prompt diagnostic investigations, appropriate treatment, and post treatment follow-up. ${ }^{10}$ Incidence and mortality of cervical cancer can be reduced by screening. ${ }^{11}$ Ensuring high levels of participation and sufficient health care infrastructure and human resources are important for a screening program to succeed. ${ }^{12}$ It is also important for screening to be guided by equity considerations for those who are more vulnerable or with lesser access to health care services because of social, economic, or demographic factors. ${ }^{13}$

Funding: No funding sources

Conflict of interest: None declared

Ethical approval: The study was approved by the Institutional Ethics Committee

\section{REFERENCES}

1. Denny L. Cervical cancer: prevention and treatment. Discov Med. 2012;14:125-31.
2. Shanta V, Krishnamurthi S, Gajalakshmi CK, Swaminathan R, Ravichandran K. Epidemiology of cancer of cervix: Global and national perspective. J Indian Med Assoc. 2000;98:49-52.

3. Biennial report (2000-2001) Lyon: IARC; 2001. WHO/IARC.

4. Parkin DM, Bray F, Ferlay J, Pisani P. Global cancer statistics, 2002. CA Cancer J Clin. 2005;55:74-108.

5. Garner EI. Cervical cancer: disparities in screening, treatment, and survival. Cancer Epidemiol Biomarkers Prev. 2003;12(3):242s-7s.

6. Planning and implementing cervical cancer prevention and control programs: a manual for managers. Seattle: AACP; Alliance for Cervical Cancer Prevention; 2004.

7. Nandakumar A, Ramnath T, Chaturvedi M. The magnitude of cancer cervix in India. Indian $\mathrm{J}$ Med Res. 2009;130(3):219-21.

8. World- both sexes estimated incidence by age. [Accessed October 30, 2014]. Available from: http://www.globocan.iarc.fr/old/age_specific_table_r .asp?

9. Human Papilloma Virus ICMR: High power Committee to Evaluate Performance of ICMR, 20122013. Disease Specific Documents for XII plan. New Delhi, India: ICMR; 2014.

10. Denny L, Sankaranarayanan R. Secondary prevention of cervical cancer. Int J Gynaecol Obstet. 2006;94(1):S65-70.

11. Hakama M, Rasanen-Virtanen U. Effectiveness of mass screening program on the risk of cervical cancer. Am J Epidemiol. 1989;(17):173-204.

12. Alliance for cervical cancer prevention (ACCP) planning and implementing cervical cancer prevention and control programs: A Manual for Managers. Seattle, WA, USA: ACCP; 2004.

13. Seema P, Paul B, Boffetta P. Meta analysis of social inequality and the risk of cervical cancer. Int $\mathrm{J}$ Cancer. 2003;105:687-91.

Cite this article as: Soni A. Pap smear screening: a retrospective study. Int J Reprod Contracept Obstet Gynecol 2017;6:1299-301. 